\title{
An Investigation of the English Articles' Acquisition by Chinese EFL Learners
}

\author{
Zhang Ying \\ English Department, North China Electric Power University, Baoding, Hebei, China
}

\begin{abstract}
The present study is conducted to find the actual acquisition process of the English article system by Chinese EFL learners. The research findings indicate that Chinese EFL learners perform poorly on the use of English articles. There is an obvious difference among learners of different proficiency levels. Learners of low proficiency level show greater instability. It is also found out that Chinese learners are more likely to show errors on omission and confusion of English articles.
\end{abstract}

Keywords: English articles; article acquisition; misuses of articles

\section{Introduction}

English articles are as a kind of determiner in English, including three categories: indefinite articles (a/an); definite article (the); zero article (Ø/null). Because of their simple structures, they can not be used alone, and are usually attached to nouns to explain meanings of them. However, English articles are much more complicated in the actual use. For many EFL learners, English articles are the most difficult part to learn and the last part to acquire completely (Master, 1990). The difficulty of the English article system is mainly due to its three characteristics: the use of articles is restricted by specific context; in the usual case, English articles do not require to pronounce with stress, which reduces the oral form of input; as function words, the form of articles does not correspond with their function (Master, 2002). For Chinese EFL learners, because of the absence of the article system in their mother tongue, they have more difficulties in the acquisition process and present more misuses in practice.

\section{Methodology}

\subsection{Research Questions}

- What are the differences in the mastery of English articles among Chinese EFL learners of different proficiency levels?

- Do different types of tasks affect participants' use of articles?

- What are the problems for Chinese EFL learners in the acquisition process of English articles? What are the reasons for these problems?

\subsection{Participants}

A total of 114 students participated in the present investigation. They are junior school students, senior school students and college students, with different learning experiences, representing primary, intermediate and advanced levels of learners respectively. Prior to the survey, they have not received any specialized training on the use of English articles.

\subsection{Instruments and Data Collection}

Two instruments are employed in the present study: a test and an interview guideline. The tasks on the test paper are 
selected from A Comprehensive Grammar of the English Language. Two parts are covered in the test: Section A consists of 25 items designed in the form of filling-in-the-blanks; Section B consists of 25 items designed in the form of error correction. The perfect score is 100 points. The grammatical functions of the 25 items in Section A are correspondent with those in Section B, but the order has been disrupted. The test was administered during the regular class time and 96 participants' test papers were valid. After the test, 10 students from three groups participated in further interview. The questions were about reasons for their misuses of English articles in the test.

\section{Results and Discussions}

\subsection{The scores of participants' use of English articles}

The results show that participants perform poorly on the use of English articles, and the average score for the test is only 55.81. The means of the three groups ascend successively: junior school $(\mathrm{m}=33.21)$, senior school $(\mathrm{m}=65.92)$, university $(m=68.28)$, indicating that learners' interlanguage system develops gradually with their proficiency levels, and higher proficiency group presents higher accuracy rate in the use of English articles.

According to the analysis of one-way ANOVA (Figure 1), the differences between junior school group and senior school group and that between junior school group and university group reach the significant level $(\mathrm{p}<.05)$. But the results do not indicate significant difference between senior school group and university group. This may be because the university group in the survey is composed of first-year non-English majors whose language level is not proficient enough to reach the advanced level.

\begin{tabular}{|cccc|}
\hline \multirow{2}{*}{ M } & N & $\begin{array}{c}\text { Mean Dif. } \\
(\mathrm{M}-\mathrm{N})\end{array}$ & Sig. \\
Junior s. & senior s. & $-32.727^{*}$ & .000 \\
& university & $-35.072^{*}$ & .000 \\
\multirow{2}{*}{ senior s. } & junior s. & $32.727^{*}$ & .000 \\
& university & -2.350 & .638 \\
university & junior s. & $35.072^{*}$ & .000 \\
& senior s. & 2.350 & .638 \\
\hline
\end{tabular}

Fig.1: One-way ANOVA among the groups

\subsection{The use of English articles in dif- ferent tasks}

In the test, the grammatical functions of the tasks in the two sections are correspondent, but the results show that participants perform quite differently on the two types of tasks. Generally, all participants perform better on Section A (filling in the blanks) than on Section B (error correction), suggesting that learners' use of English articles are influenced by different tasks. Through T-test, only the junior school group presents significant difference in the performance on different tasks, indicating that less proficient language learners' are restricted greatly by their interlanguage system and their use of a certain article is probably at random.

\subsection{The misuse of English articles}

As indicated in Figure 2, participants of different proficiency levels commit different types of errors in using English articles. They are more likely to show errors on omission and confusion. To explore further the reasons, the following interview is conducted.

\begin{tabular}{|lccc|}
\hline \multicolumn{1}{|c}{ Types of misuse } & Jun. & Sen. & Uni. \\
omission & $48.4 \%$ & $22.3 \%$ & $20.6 \%$ \\
confusion 'a/the' & $44.9 \%$ & $21.7 \%$ & $19.5 \%$ \\
overuse 'the' & $9.2 \%$ & $11.8 \%$ & $12.0 \%$ \\
overuse 'a' & $31.4 \%$ & $7.0 \%$ & $6.4 \%$ \\
\hline
\end{tabular}

Fig.2: Frequency of misuses of articles 


\section{- The omission of English articles}

EFL learners' omission of English articles is mainly because of interlingual errors (Richards, 1971). English and Chinese are two different language systems. There is no article system in Chinese. Under the influence of negative transfer, Chinese EFL learners tend to omit using articles when necessary. However, the effect of negative transfer is reduced with the development of learners' proficiency levels. In the present study, the frequency of omission of English articles by junior school group is $48.4 \%$, which is much higher than the other two groups, indicating learners' increasing accumulation of knowledge about the target language helps to reduce the interference of their mother tongue on the acquisition of English articles.

In the following interview, participants state that they tend to translate the English item into Chinese and then judge when they don't know whether a certain article is used or not. This indicates that students have formed the habit of translation into Chinese with excessive translation exercises in teaching and learning practice, but because of the differences between Chinese and English, learners often make wrong judgments which hinder their acquisition process. Besides, the similar structures in the target language system lead to misuses of articles by participants. For example, question 11 in Section A: Lily said her job was paid by _day. The answer is "the", referring to measurement unit. In the test, $43.7 \%$ participants omit the definite article. In the interview, participants mention that they don't use the definite article for question 11 is because "the" is not used in the structures "by bus / bike/boat/car, by myself". Question 18 in Section B: *Can you play guitar? $34.2 \%$ participants can't identify the error in the sentence, because "the" is not used in the structures "play piano, play football/basketball". This shows that learners' use of general rules in the target language is affected by special rules in some similar structures, which let them make wrong assumptions. In addition, another difficulty for learners is that they often overgeneralize the usage of English articles. For example, question 20 in Section A: Chang Jiang River flows into the East China Sea. $41.9 \%$ participants don't use any article. They know clearly about the rules that before the proper nouns, the definite article is not used while ignoring the rule that the definite article must be used before some other proper nouns.

- The confusion of English articles

For the confusion of "a/the", the junior school group makes more errors than the other two groups. This is mainly because the junior school group is influenced by their limited exposure to the target language, and their proficiency level is so low that they don't have a good command of the general rules and some fixed usage. For example, question 7 in Section B: *Sun rises in the east. The answer is to add "the" before "sun", but $73.2 \%$ junior school participants add "a" before "sun". In the interview, junior school participants point out that that they add "a" because the noun "sun" is a singular form and is mentioned for the first time in the sentence, indicating that learners of lower proficiency level only know of a part of the general rules and usage, so they are greatly restricted by the limited grammatical rules and knowledge about the target language. As the improvement of proficiency level, learners know more about the grammatical rules of the target language, cultivate a better ability to judge and have a better command of the English article system. Therefore, in the investigation, senior school group and university group present fewer problems on the confusion of English articles. 


\section{- The overuse of English articles}

The overuse of English articles includes the overuse of the indefinite article and the definite article.

The usage of the definite article is very complex, and it can be used for both specific reference and generic reference. The study shows that with the development of learners' language proficiency, the frequency of overuse of the definite article is higher, indicating that learners tend to over-generalize the use of the definite article in their acquisition process (Huebner, 1983). The interview shows that one of the main reasons for the overuse of the definite article is that participants have difficulties in judging the properties of nouns. Besides, learners' inadequate knowledge about the general rules on the use of the definite article also leads to the overuse. Another significant factor is that the unsystematic teaching of English articles makes learners only grasp a part of grammatical rules and some special rules lay a heavy burden for learners, and the intensive training of the definite article in class also leads to learners' misuses of the definite article.

In the study, the overuse of the indefinite article is mainly committed by the junior school group, and its frequency of misuses is $31.4 \%$. It is found that this is mainly due to participants' inadequate knowledge of grammatical rules and limited exposure to the target language. Besides, the number of nouns and the modifiers before the noun also influence the judgment made by junior school participates, indicating learners of low proficiency level are greatly restricted by their interlanguage system, thus fail to analyze the function of terms in sentences.

\section{Conclusion}

The present study shows that Chinese EFL learners perform poorly on the use of English articles. Learners' acquisition process is influenced by their language proficiency levels and the accumulation of knowledge about the target language. It is also found that learners of low proficiency level present an obvious difference on different tasks, which shows their greater instability on the use of English articles. In terms of reasons for the misuses of English articles, in addition to the complexity of the English article system itself, the teaching process affect learners' use of articles greatly. Therefore, teachers should emphasize the distinction between general rules and irregular forms to help learners avoid over-generalization and unnecessary translation to reduce the influence of negative transfer of learners' mother tongue on the acquisition process.

\section{References}

[1] Huebner, T. (1983). A longitudinal analysis of the acquisition of English [M]. Ann Arbor, Michigan: Karoma Press.

[2] Master, P.. Teaching the English articles as a binary system[J]. TESOL Quarterly, 1990(24): 461-489.

[3] Master, P. Information structure and English article pedagogy[J]. System, 2002(30).: 331-348.

[4] Quirk, R.,S.Greenbaum, G.Leech,\& J.Svartvik. A comprehensive grammar of the English language[M]. Harlow: Longman, 1985.

[5] Richards, J. Error analysis: Perspectives on second language acquisition[M]. London: Longman Group,Ltd., 1971. 